\title{
An Analytical Model for Optimizing the Combination of Energy Sources in a Single Power Transmission Network
}

\author{
Massimo de Falco and Nicola Mastrandrea \\ Department of Engineering and Management, University of Salerno, Via Giovanni Paolo II, Salerno, 84084 Fisciano, Italy \\ Correspondence should be addressed to Nicola Mastrandrea; nmastrandrea@unisa.it
}

Received 27 May 2014; Revised 9 October 2014; Accepted 9 October 2014; Published 18 November 2014

Academic Editor: Jing Shi

Copyright (c) 2014 M. de Falco and N. Mastrandrea. This is an open access article distributed under the Creative Commons Attribution License, which permits unrestricted use, distribution, and reproduction in any medium, provided the original work is properly cited.

\begin{abstract}
The increasing amount of renewable energy currently being added to distribution networks presents new challenges and opportunities to system operators. This situation further complicates the operators' tasks in dealing with changing net loads and balancing. The current work provides an analytical model to assist systems operators in stabilizing power generation and lowering total costs, through optimization of choices in the combination of programmable fossil sources and nonprogrammable renewable sources. The study first examines the various programmable and renewable energy sources that appear broadly suitable and economically appealing for combination. Next we identify the most important factors determining the potential integration of the sources in the system. Based on this introductory information we then develop the model for the selection of the appropriate mix of sources to achieve stable production. In developing the model we define indicators to evaluate and select the best configurations of the sources included in a particular combination. Next we apply the model to a specific case study and finally reexamine the interdependencies among all the variables of the model, to provide a better understanding of its dynamics and results.
\end{abstract}

\section{Variability in Energy Sources and Loads}

Electricity cannot be stored on a massive scale in an economical way; thus system operators must constantly balance power supply and demand to maintain overall stability and power quality. Serious mismatches could cause local power interruptions, blackouts, or breakdowns in the entire system.

Conventional hydroelectricity and coal, oil, or gas thermal generation provide steady and predictable feeds to the energy grids, with precise scheduling of output. On the other hand, renewable energy sources such as wind and solar power are typically variable, meaning that they provide intermittent output that cannot be completely and accurately predicted. The increasing application of renewable energy technologies to feed into power grids is a challenge to the system operators, who must then deal with more unpredictable net loads and more complex balancing [1]. In fact the "nonprogrammable" nature of renewable energy sources refers not to the actual fact of production, but rather to the challenges in controlling the input of the energy generation to the grid in a profitable manner [2].
Possible solutions include

(1) energy storage (e.g., pumped hydroelectric and compressed air energy storage, chemical batteries, and active load management) [3];

(2) geographic diversification of installation sites;

(3) combination of energy sources.

The option of energy storage as the solution to programming still presents important technical and financial limits. Diversification of renewable sources and installations can indeed reduce overall variability; however it does not eliminate the intrinsic variability of the sources. Thus one of the current challenges for network managers is the question of how to combine various energy sources in a manner that best controls variability over the entire distribution system.

\section{Possibilities and Advantages of Combining Energy Sources}

To combine energy sources means to integrate two or more power plants drawing on different sources. The aim of our 
research is to support system operators in the integration of new nonprogrammable power plants with new or existing power plants providing programmable generation. The resulting power systems, of two or more plants, will utilize shared transmission capacity, in which some amount of the more programmable generation will be sacrificed to control and transmit the nonprogrammable production. The objective of the current paper is to provide a model for selection of sources and management of the system in a manner that renders the resulting overall production as stable and financially attractive as possible.

There are a variety of benefits to combining planned and nonprogrammable generation including reductions in fuel consumption and higher overall system efficiency, along with reduction of $\mathrm{CO}_{2}$ emissions. Development of combined systems also stabilizes production costs by reducing the unpredictable impact of changing fuel costs, which amount to $70 \%$ of total costs in thermal power plants. Finally, controlled integration of renewable technologies unlocks new resources without the necessity of increasing transmission capacity, since in the combined system all energy is carried by the preexisting system for programmable sources.

\subsection{Preliminary Identification of Suitable Sources for Combi-} nation. We first provide a preliminary identification of the most suitable energy sources for combination with others, through a brief analysis of their economic competitiveness and technical feasibility.

We choose against renewable energy sources that are severely limited in their specific geographic location, such as geothermal and hydro generation. For the current paper we also choose against biomass but in this case for the primary reason that identification of the price of this material as fuel for power generation requires careful consideration that goes beyond the general approach of the study. Still, when such price analysis is correctly conducted, the model presented in the paper would be fully able to consider combination of the biomass source.

The USA Energy Information Administration Annual Energy Outlook [4] (Figure 1) provides a good summary of the costs of the different energy conversion technologies in a midterm perspective.

From the graph we can readily see that in the midterm, the most appealing fossil based sources for combination with renewable sources will be natural gas (advanced combined cycle), natural gas (conventional combined cycle), and conventional coal. For the renewable sources, on-shore wind is clearly the most competitive technology, followed by the solar sources. In the current study we will consider direct photovoltaic (PV) conversion and two concentrated solar power (CSP) technologies, also known, specifically integrated solar-gas combined cycle and hybrid solar-gas turbine.

2.2. Factors Determining the Possibility of Integration. In this section we identify the characteristics of energy sources that are most important for determining their potential integration in a combined system, and which must thus be included in our model. We refer to these as "integration factors."

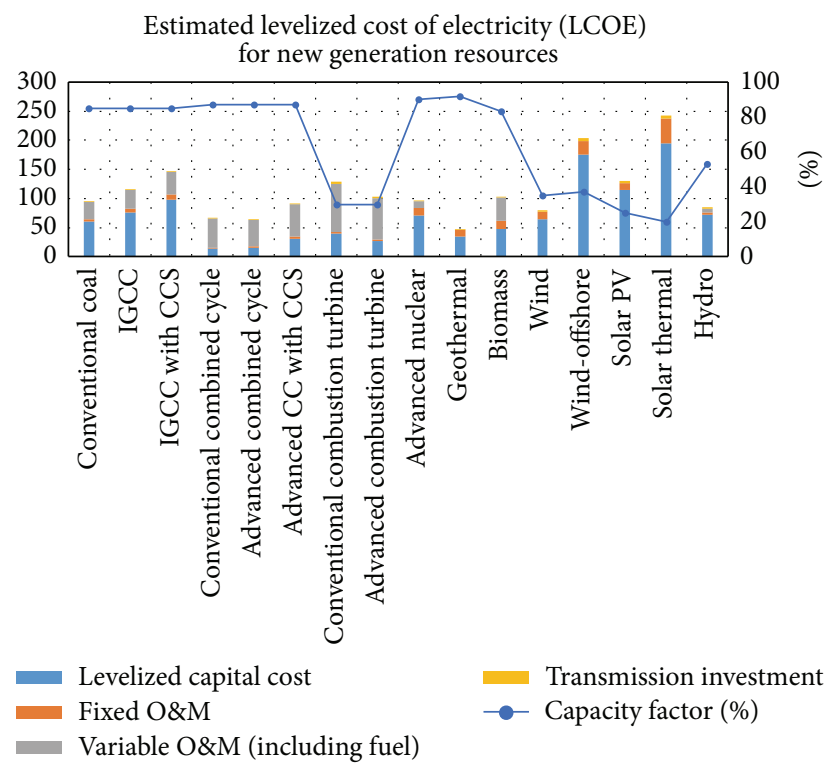

FIGURE 1: Estimated levelized cost of new generation resources (2019). Source: the Energy Information Administration Annual Energy Outlook, 2014.

The first step is the evaluation of variability in the renewable sources. Effective modelling requires precise identification of the minute-to-minute variability (Var. min-to-min) of the different sources (Figure 2). Lower variability generally makes a power source more compatible for combination with other sources. In particular, the analysis of this factor must identify the maximum variability, occurring on the days with the greatest minute-to-minute variation.

In the case of fossil fuel technologies, the evaluation of plant flexibility is more important. Flexibility depends primarily on the plant's efficiency under partial load and the ramp rate or potential rate of change in output. The factor of partial efficiency is evaluated in the form of efficiency curves for the specific plant under consideration, which can then be fed into the model for combined sources. Ramp rate is expressed as the maximum variation in power that a given plant can attain in one minute, as a percentage of the plant's total capacity per minute. The values for this factor range from $2 \%$ to $3 \%$ per minute in the case of coal plants to over $10 \%$ per minute in the case of the latest generation of flexible gas plants.

A technical consideration common to both renewable and programmable technologies is the capacity factor (fc). This is the ratio between the actual output of a single plant or group of plants in a given place over a period of time and the energy that would have been produced by the same plants if these had operated at full potential over the same time.

2.3. Modelling the Combinations of Energy Sources. The purpose of the model is to describe the procedure to find the optimal combination of energy sources, beginning from the preliminary selection of appealing energy sources and applying the integration factors in an analytical manner.

2.3.1. A First Choice among Combinations. As a first step, the model takes the different sources as inputs and combines 

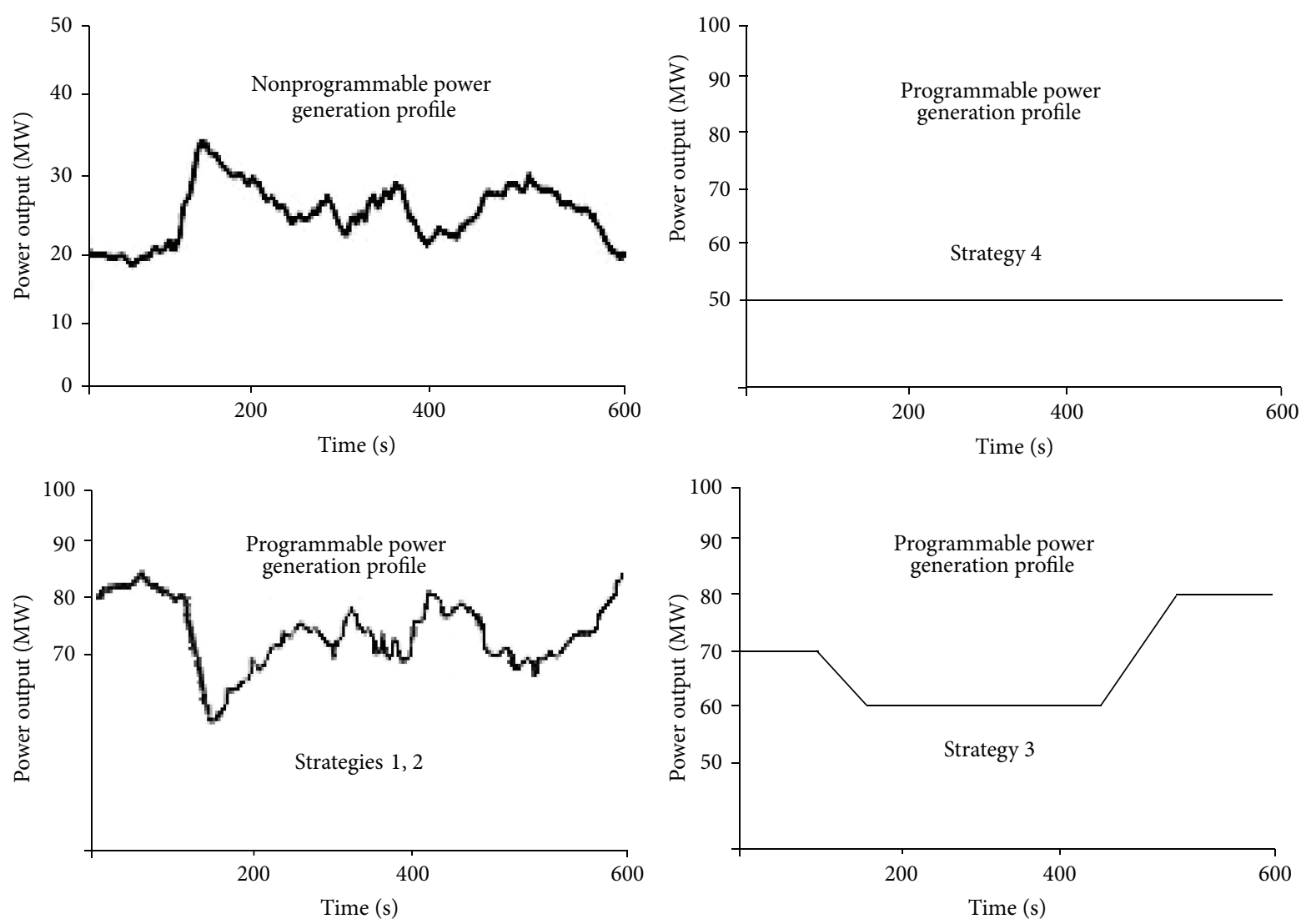

Figure 2: Productive strategies.

them in all the different possible sets. However it is immediately apparent that not all the potential sets will offer appropriate energy and economic characteristics. Thus the model next takes a qualitative approach to carry out a first elimination of combinations of sources that are not well structured, particularly in terms of variability and flexibility factors.

For example in the case of a programmable plant with a low ramp rate the model excludes all those combinations with more than one additional font and with any fonts demonstrating high values of maximum variability.

The model also excludes combinations involving more than two sources having low capacity (except for CSP), due to their inherent failure to offer sufficient flexibility in production.

Finally, the model automatically eliminates combinations using more than one plant using the same renewable font (e.g., photovoltaic with CSP), since such combinations would intrinsically reduce the total flexibility of the system and in many cases would result in summation of the same type of variability.

2.3.2. Modelling Dimensioning and Production Strategies. The model for dimensioning examines the individual combinations chosen in the previous stage and quantifies the maximum percentage of integration for the variable sources and the appropriate production strategy to maintain acceptable levels of stability in production.
The first step is to compare the values of minute-tominute variability of the different variable sources and identify the maximum among them, which will constrain the entire system. Next we calculate the "combination coefficient" in the case of full load-following for all parts of the system, meaning the case where the overall production is equal to the maximums of all the stand-alone systems. The combination coefficient (CC) is equal to maximum variability of the nonprogrammable sources divided by the ramp rate of the programmable power plant as shown in (1):

$$
\mathrm{CC}=\frac{\max \{\text { Var. } \min \text {-to- } \min \} i=1, \ldots, N}{\text { ramp rate }} .
$$

The inverse of this coefficient gives us the maximum permissible integration of variable sources in terms of percentage of the programmable power plant size. A high value for this coefficient means that the programmable thermoelectric plant will succeed in balancing variations from renewable sources even under extreme conditions. Taking account of this consideration, the model also chooses the operational production strategy, in function of some recommended threshold values, as shown in Table 1.

Productive strategies [5] are as follows:

(1) full load-following: the programmable power plant follows min-to-min renewable power fluctuations; 
TABLE 1: Threshold indicators for production strategies.

\begin{tabular}{lc}
\hline Productive strategy chosen & Threshold indicator \\
\hline Full load-following & $39 \%$ \\
Partial load-following & $19 \%$ \\
Variable throttle back & $10 \%$ \\
Fixed throttle back & $<9 \%$ \\
\hline
\end{tabular}

(2) partial load-following: the programmable power plant follows min-to-min renewable power fluctuations ignoring little variations;

(3) variable throttle back: this strategy is based on a daily/ seasonal piecewise constant power generation profile;

(4) fixed throttle back: this strategy is based on a seasonal constant power generation profile.

Once the strategy is chosen the model calculates the maximum percentage that is technically possible for integration, as the inverse of the combination coefficient. In the case of a real-time load-following strategy (full or partial) we have already seen how the integration ratio is calculated. In case of non-real-time scenarios, the maximum integration ratio will depend on the programmable power plant operating characteristics, specifically the efficiency curves and the value of the turndown point $(t \%)$, meaning the percentage of the plant

$$
\mathrm{cc}=\frac{1}{(1-t \%)}
$$

capacity under which the plant can no longer be operated in a stable manner.

2.3.3. Model for Evaluation of the Combinations. Once the coefficient of maximum integration is fixed for every combination, the model evaluates these combinations through calculation of a series of technical, economic, and financial indicators, applied to the different potential configurations of power and integration for each combination. In conducting the evaluation, the model searches for the best possible configuration for every combination of power sources under examination.

First we fix the overall size of the combination:

$$
P_{\mathrm{tot}}=P_{f}+\sum_{i=1}^{N} \mathrm{fi} \cdot P_{\mathrm{ti}}, i, \quad \sum_{i=i}^{N} \mathrm{fi} \leq 1 .
$$

Next, for each combination, we identify the programmable power plant average efficiency over the 8760-hour year, given its integration with the variable production under the chosen strategy. In case of a real-time following strategy (full or partial), the average efficiency is calculated as

$$
\eta_{\text {avg }}=\eta_{\text {parz }} \cdot \mathrm{fc}_{\text {int }}+\left(1-\mathrm{fc}_{\text {int }}\right) \cdot \eta_{\text {nom }} \cdot
$$

In case of a non-real-time following strategy (fixed or variable throttle back), the average efficiency is derived by examining the partial efficiency curve for the programmable power plant, for the output level "full output" minus "integrated output" $\left(P_{f}-P_{\text {int }}\right)$.
With the average efficiency of the thermal power plant identified, the model next calculates, for each potential combination, the annual power generation contributions from the different sources:

$$
\begin{gathered}
E_{\mathrm{tot}}=E_{f}=P_{f} \cdot 8760 \cdot \mathrm{fc}_{f}[\mathrm{MWh}], \\
E_{i}=P_{\mathrm{ti}}, i \cdot \mathrm{fc}_{\mathrm{int}}, i \cdot 8760[\mathrm{MWh}] .
\end{gathered}
$$

Knowing $E_{\text {tot }}$ for each strategy, we are now able to calculate the capacity factor of the programmable power plant after the integration of the nonprogrammable sources:

$$
\text { fc, } f=\frac{E_{\text {tot }}-\sum_{i=1}^{N} E_{i}}{P_{f} \cdot 8760}
$$

This modified capacity factor is used to calculate the fuel cost for the fossil power plant, following the integration envisioned:

$$
\mathrm{CC} \frac{E_{f} \cdot \mathrm{CUC}}{\eta e l, \mathrm{avg}}=\frac{P_{f} \cdot 8760 \cdot \mathrm{fc}_{f} \cdot \mathrm{CUC}}{\eta e l, \mathrm{avg}}[€] .
$$

The overall capital cost of the combined sources under consideration can be calculated on the basis of the unit costs:

$$
\operatorname{cinv}=P_{f} \cdot \operatorname{cinv}_{f}+\sum_{i=1}^{N} \mathrm{fi} \cdot P_{\mathrm{ti}}, i \cdot \operatorname{cinv}_{i} ;
$$

while the revenues from energy sales to the grid can be calculated from the annual production:

$$
\text { Ree }=\text { pue } \cdot E_{\text {tot }}[€] .
$$

In the event of incentives for generation from renewable sources, governatives subsidies for renewable generation are calculated:

$$
\text { ifr }=\sum_{i=1}^{N} E_{i} \cdot \mathrm{ifr}, i[€] .
$$

Having completed these calculations of costs and revenues, the model proceeds to selection among the alternate configurations of the combinations of sources. This stage requires application of several energy and financial indicators.

The first energy indicator calculated is the fuel consumption variation, calculated as the difference between annual fuel cost in the case of integration and the annual fuel costs in the stand-alone case. In the case that the indicator is negative the configuration under consideration is immediately discarded.

The second indicator is the efficiency variation, calculated as the difference between the overall efficiency of the combination and the efficiency of the stand-alone programmable plant. A negative value for this indicator results in elimination of that particular configuration of the combined sources from those remaining in consideration.

In the last selection stage the model conducts a financial analysis, consisting of calculation of a series of indicators shown in Table 2, in order to complete the final selection of the best possible energy source combinations. 


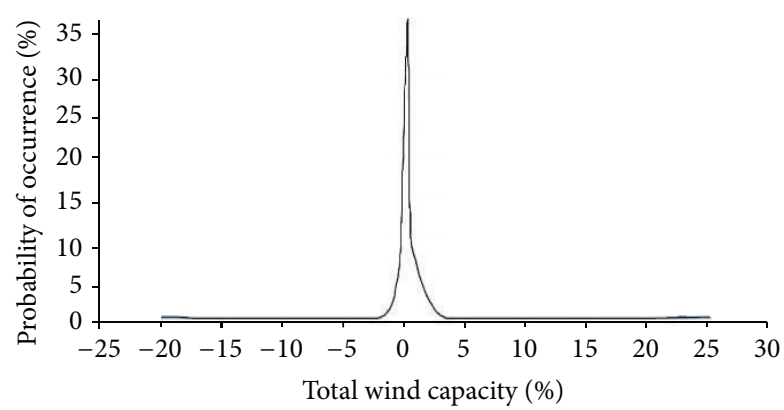

Figure 3: Example of minute-to-minute variability in wind power output (data source: Platts, data from National Renewable Energy Laboratory).

TABLE 2: Financial assumptions and indicators.

\begin{tabular}{l}
\hline Financial indicators \\
\hline Return on equity \\
Net present value \\
Profitability \\
Payback period \\
Internal rate of return
\end{tabular}

2.4. A Simulated Case Study. This section demonstrates the application of the model to a case study situation.

2.4.1. Case Study Input Parameters. Tables 3 and 4 present the technical and economic data inserted in the model for the case study [6].

2.4.2. Modelling the Dimensioning and Evaluating the Configurations. In this section we illustrate the application of the dimensioning stage of the model for the case study combination of natural gas combined cycle (NGCC) and wind energy sources, followed by evaluation of the different potential configurations.

First we identify the maximum min-to-min variability of the wind resource. For the case study, this results as $24 \%$ (Figure 3).

Given the NGCC plant ramp rate of 5\%, the model next calculates the combination coefficient, in this case 4.8 , and the maximum potential percentage of power integration, in this case $21 \%$.

Table 5 illustrates the different configurations of wind energy contribution to the NGCC + wind combination.

Table 6 shows the evaluation stage for the NGCC + wind combination.

2.4.3. Case Study Model Results. Of the 31 combinations possible, only 10 arrive at the final stage, as shown in Table 7.

Most of the combinations excluded are those using coal as the fossil fuel source and photovoltaic as the renewable source. This is due to the high capital cost of photovoltaic and the low flexibility of coal, combined with low capacity factors.

The energy mix of the different combinations, and in particular the renewable energy share, depends on the

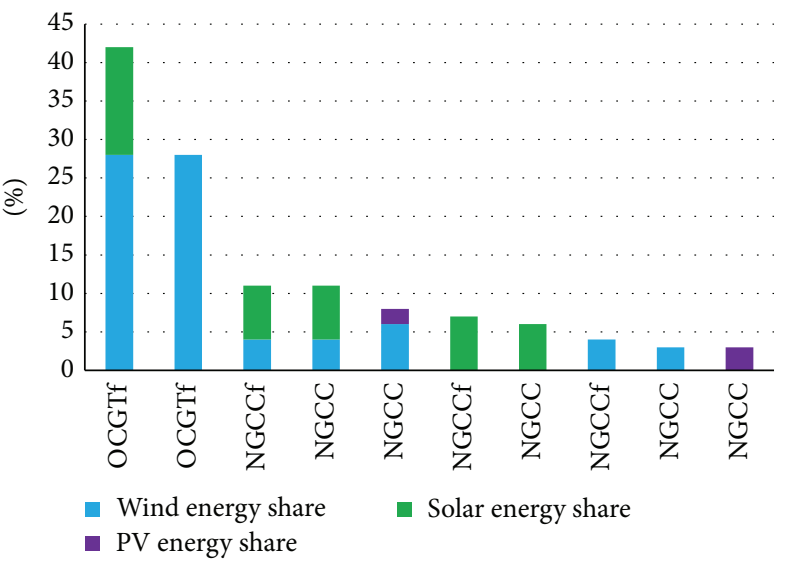

FIGURE 4: Energy mix of the renewable energy share in the "optimal combinations."

dimensioning and subsequent optimization stages of the model.

From Figure 4, we observe that OCGT plants can integrate a higher renewable energy share than NGCC plants. This difference is determined by the OCGT plants having a greater ramp rate and a much lower capacity factor.

In another important consideration, as seen in Figure 5, the combination of energy sources (in red) results in only a modest reduction in total capacity factor compared to the stand-alone cases (in yellow).

The results from the model also seem to confirm our original hypotheses that combination with renewable sources will result in a reduction of total costs and lower the influence of variable costs due to fossil fuel prices. This is observed in the table of costs per unit of production ( $€ / \mathrm{MWh})$, as seen in Figure 6.

From a financial point of view, not all the combinations have the same stability, as seen in Figure 7. In fact OCGT combinations with a high renewable energy share are very appealing from an energy and economic point of view but fail to reach sufficient profitability for safe investment. We also observe that combinations with NGCC are most profitable when they involve CSP or wind sources.

2.5. Interdependency Analysis. To better understand the results from the simulation, this section provides an analysis 
TABLE 3: Case study technical parameters.

\begin{tabular}{lccc}
\hline Technologies & Capacity factor & Efficiency & $\begin{array}{c}\text { Ramp } \\
\text { Rate/Max. var. }\end{array}$ \\
\hline NGCC & $85 \%$ & $47 \%$ & $5 \% / \mathrm{min}$ \\
NGCC Flexible & $87 \%$ & $61 \%$ & $10 \% / \mathrm{min}$ \\
OCGT Flexible & $32 \%$ & $36 \%$ & $13 \% / \mathrm{min}$ \\
PC & $84 \%$ & $38 \%$ & $1-3 \% / \mathrm{min}$ \\
PV & $25 \%$ & - & $50 \% / \mathrm{min}$ \\
CSP & $18 \%$ & $13.5 \%$ & - \\
Wind & $34 \%$ & - & $30 \% / \mathrm{min}$ \\
\hline
\end{tabular}

TABLE 4: Case study economic parameters.

\begin{tabular}{lccc}
\hline Technologies & Capital cost $(€ / \mathrm{kW})$ & O\&M fixed cost $(€ / \mathrm{MW})$ & O\&M variable cost $(€ / \mathrm{MWh})$ \\
\hline NGCC & 880 & 10.4 & 32.8 \\
NGCC flexible & 950 & 10.4 & 30.3 \\
OCGT flexible & 550 & 10.5 & 45.2 \\
PC & 2650 & 19.6 & 17.5 \\
PV & 5500 & 18.5 & - \\
CSP & $4200-8400$ & 6.7 & - \\
Wind & 2350 & 38.5 & - \\
\hline
\end{tabular}

TABLE 5: Dimensioning the wind contribution to NGCC + wind combination.

\begin{tabular}{lccccc}
\hline Wind farm size (MW) & 40 & 30 & 20 & 10 & 5 \\
Percentage wind capacity & $20 \%$ & $15 \%$ & $10 \%$ & $3 \%$ \\
\hline Wind farm capacity factor & & \multicolumn{3}{c}{ Wind energy share } \\
\hline $15 \%$ & $3.00 \%$ & $0.60 \%$ & $0.12 \%$ & $0.02 \%$ & $0.03 \%$ \\
$20 \%$ & $4.00 \%$ & $0.80 \%$ & $0.16 \%$ & $1.25 \%$ & $1.50 \%$ \\
$25 \%$ & $5.00 \%$ & $3.75 \%$ & $2.50 \%$ & $0.01 \%$ \\
$30 \%$ & $6.00 \%$ & $4.50 \%$ & $3.00 \%$ & $0.63 \%$ \\
$35 \%$ & $7.00 \%$ & $5.25 \%$ & $3.50 \%$ & $0.75 \%$ \\
$40 \%$ & $8.00 \%$ & $6.00 \%$ & $4.00 \%$ & $2.00 \%$ & $1.00 \%$ \\
\hline
\end{tabular}

Note: NGCC size $=200$ MW.

TABLE 6: Evaluation model for NGCC + wind combination.

\begin{tabular}{|c|c|c|c|c|c|c|c|}
\hline Plant \# 1 & Plant \# 2 & $\begin{array}{c}\text { Plant \# } 1 \text { size } \\
(\mathrm{MW})\end{array}$ & $\begin{array}{c}\text { Wind energy } \\
\text { share }\end{array}$ & $\begin{array}{l}\text { Nominal } \\
\text { efficiency }\end{array}$ & $\begin{array}{l}\text { Overall } \\
\text { efficiency }\end{array}$ & $\begin{array}{c}\text { Efficiency } \\
\text { variation }\end{array}$ & $\begin{array}{c}\text { Internal } \\
\text { interest rate }\end{array}$ \\
\hline \multirow{9}{*}{ NGCC } & \multirow{9}{*}{ Wind } & \multirow{3}{*}{300} & $8 \%$ & $55 \%$ & $54 \%$ & $-1 \%$ & $19 \%$ \\
\hline & & & $6 \%$ & $55 \%$ & $58 \%$ & $3 \%$ & $22 \%$ \\
\hline & & & $3 \%$ & $55 \%$ & $57 \%$ & $2 \%$ & $25 \%$ \\
\hline & & \multirow{3}{*}{210} & $8 \%$ & $55 \%$ & $54 \%$ & $-1 \%$ & $19 \%$ \\
\hline & & & $5 \%$ & $55 \%$ & $57 \%$ & $2 \%$ & $23 \%$ \\
\hline & & & $2 \%$ & $55 \%$ & $56 \%$ & $1 \%$ & $25 \%$ \\
\hline & & \multirow{3}{*}{150} & $8 \%$ & $55 \%$ & $54 \%$ & $-1 \%$ & $18 \%$ \\
\hline & & & $5 \%$ & $55 \%$ & $58 \%$ & $3 \%$ & $22 \%$ \\
\hline & & & $3 \%$ & $55 \%$ & $57 \%$ & $2 \%$ & $24 \%$ \\
\hline
\end{tabular}




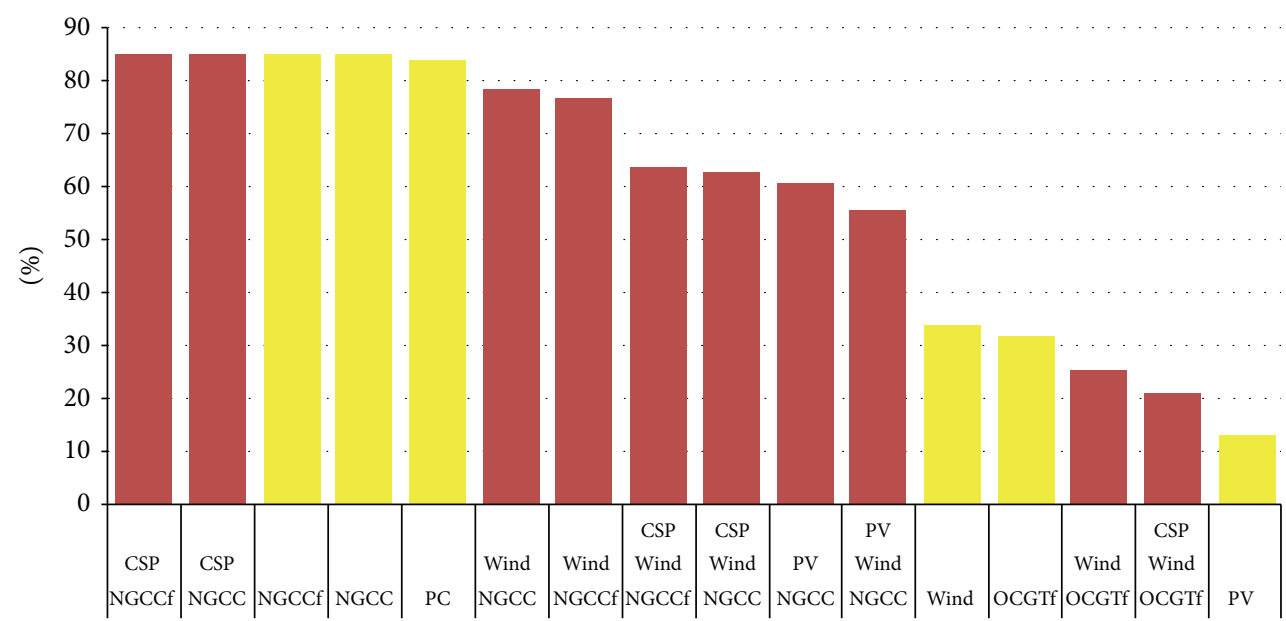

FIGURE 5: Total capacity factor of combined energy sources and stand-alone cases.

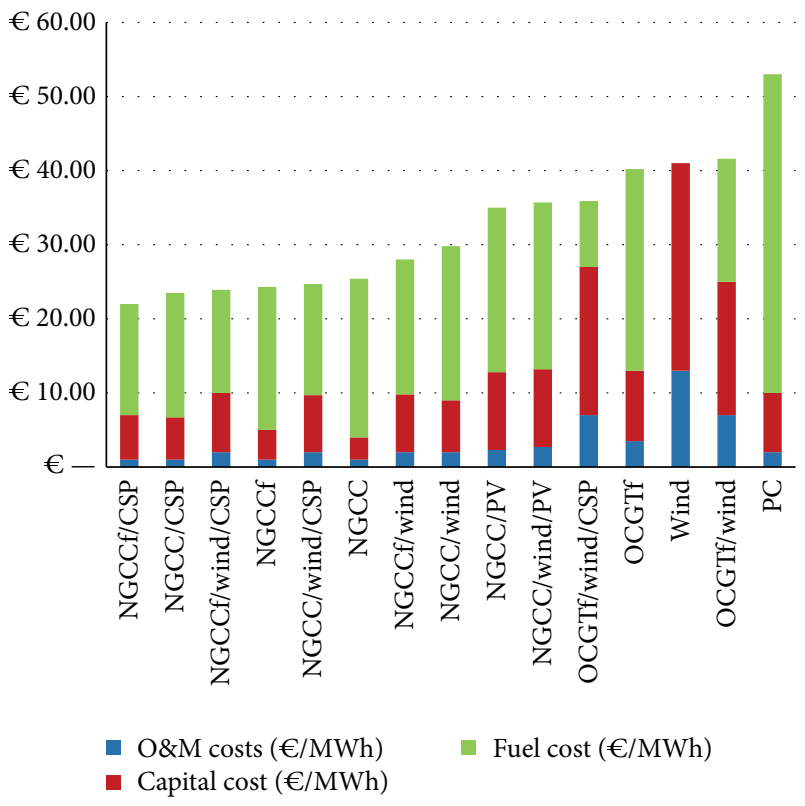

FIGURE 6: Unit costs of production under energy source combinations (€/MWh).

TABLE 7: Best combinations of energy sources (case study).

\begin{tabular}{|c|c|c|c|c|c|c|}
\hline NGCC & $\mathrm{NGCC}_{\mathrm{F}}$ & $\mathrm{OGT}_{\mathrm{F}}$ & Wind & CSP & $\mathrm{PV}$ & Operative scenario \\
\hline$\times$ & & & $\times$ & & & Imperfect following \\
\hline$x$ & & & & & $x$ & Variable throttle back \\
\hline$\times$ & & & & $\times$ & & $100 \%$ following \\
\hline$x$ & & & $x$ & $x$ & & $100 \%$ following \\
\hline \multirow[t]{6}{*}{$x$} & & & $x$ & & $x$ & $100 \%$ following \\
\hline & $\times$ & & $x$ & & & $100 \%$ following \\
\hline & $\times$ & & & $x$ & & $100 \%$ following \\
\hline & $x$ & & $x$ & $x$ & & $100 \%$ following \\
\hline & & $\times$ & $x$ & & & $100 \%$ following \\
\hline & & $\times$ & $\times$ & $\times$ & & $100 \%$ following \\
\hline
\end{tabular}

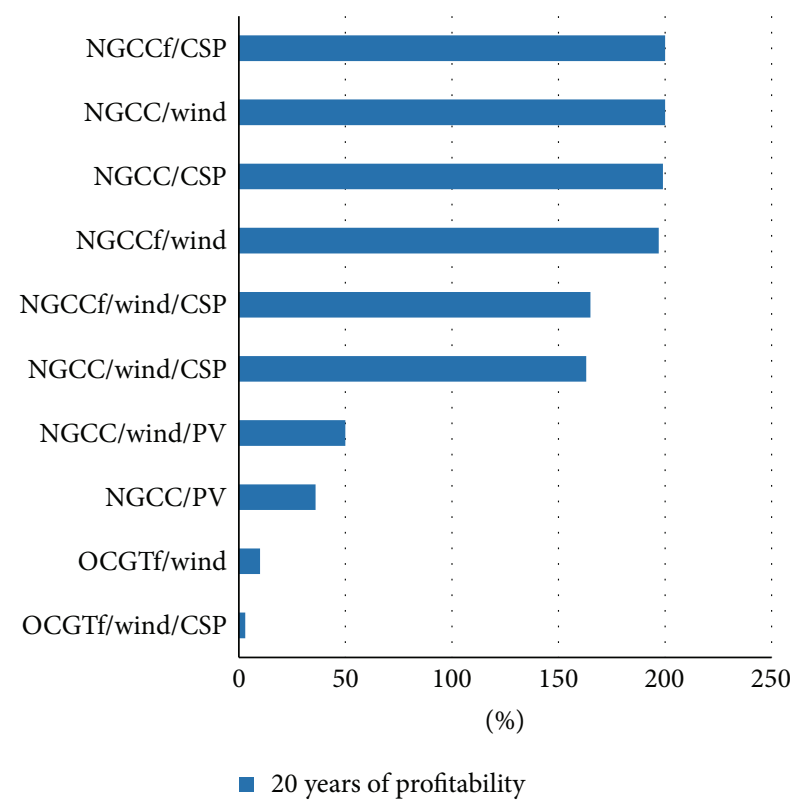

FIGURE 7: Energy combination profitability (at 20 years).

of the interactions between all the variables, both among the various factors and between the factors and indicators.

2.5.1. Interdependency Mapping. The map seen in Figure 8 shows the interactions between the input factors (white/blue and blue) derived from the first stage of analysis, and the energy and economic indicators (red). The connecting lines and symbols "+" and "-_" indicate proportional direct positive and negative influence between the factors, while the green lines show the relative analytical formulae. From the map we observe that the dominant factor is the energy share, which, limited by its partial efficiency (formula $\% E_{\max }$ ), is in turn directly linked to the profitability of the particular combined energy sources. Thus beginning from very limited initial data, in a few steps we can optimize the influences on the factor 


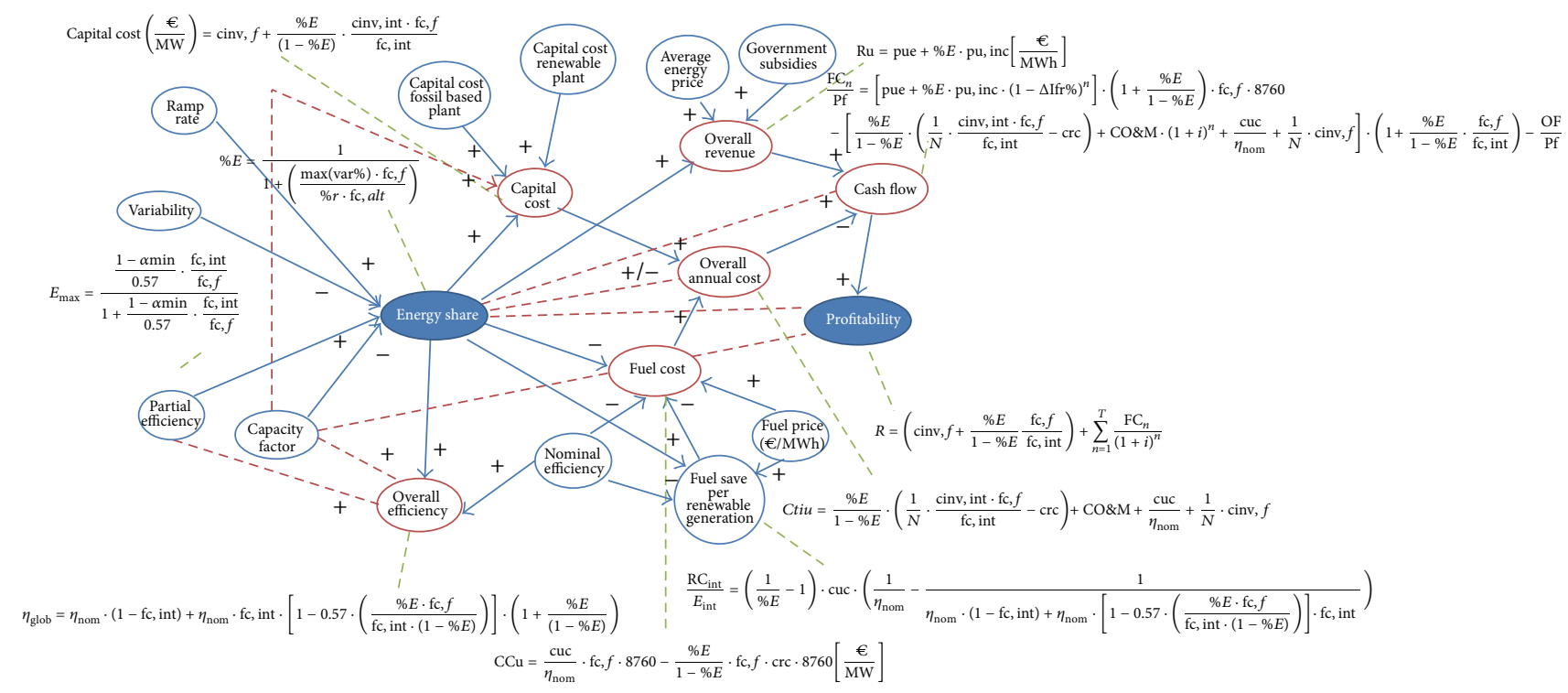

FIGURE 8: Interdependency map.

of energy share and identify the best configuration of the different energy sources in that particular combination.

\subsubsection{Interaction between Technical Factors and Renewable} Energy Share. We define renewable energy share (RES) as the percentage of energy derived from variable sources:

$$
\% E=\frac{E_{\text {int }}}{E_{\text {int }}+E_{f}} .
$$

Recalling the formulae used for the model of dimensioning and taking the case of a real-time following strategy, we see how RES $(\% E)$ depends on technical factors; see Figure 8.

This formulation of RES confirms the results of the simulation. In fact as we can see that, from Figure 9, under conditions of equal flexibility (equal ramp rate), open cycle OCGT plants will have a higher RES than combined cycle NGCC plants, due to their lower capacity factor.

\subsubsection{Interaction between Economic Factors and Renewable} Energy Share. The annual plant costs consist of the sum of the capital, operations and maintenance, and fuel costs. Expressing all of these costs as a function of RES (\%E), we have

$$
\begin{aligned}
\text { Ctiu }= & \frac{\% E}{1-\% E} \cdot(\underbrace{\frac{1}{N} \cdot \frac{\mathrm{cinv}, \text { int } \cdot \mathrm{fc}, f}{\mathrm{fc} \text { int }}}_{\text {Renewable Capital Cost }}-\underbrace{\mathrm{crc}}_{\text {Reduction Fuel Cost }}) \\
& +\mathrm{CO \& M}+\frac{\mathrm{cuc}}{\eta_{\text {nom }}}+\frac{1}{N} \cdot \operatorname{cinv}, f .
\end{aligned}
$$

The trend in annual plant cost depends on the comparison between annual capital cost of the integrated plant and an energy indicator that represents the "reduced fuel cost" per $\mathrm{MWH}$ produced from renewable sources ( $\mathrm{rfc}$ ).

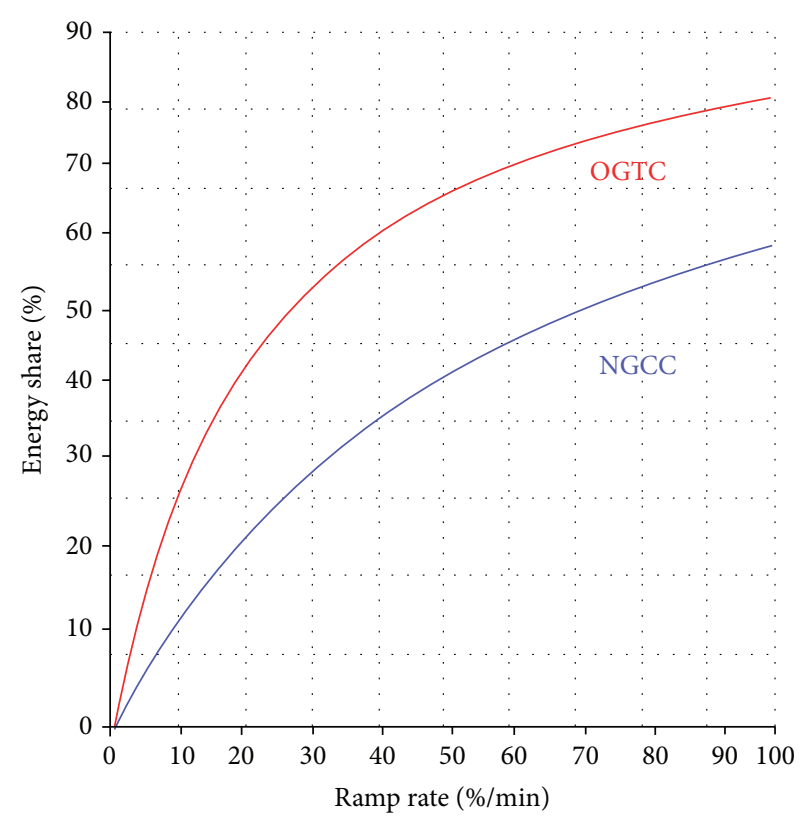

FIGURE 9: Interdependency between ramp rate and energy share.

In essence, the trend in total costs in function of renewable energy share will be increasing in the case that the annual savings of fuel per unit of energy produced from the renewable sources is greater than the annual capital cost of the renewable plant and decreasing in the opposite case.

If the annual capital cost is higher than $\mathrm{rfc}$, then the total costs function will be increasing with increase of energy share; otherwise the annual plant costs will be decreasing.

This means that with an increase in the annual plant costs of the combination, the model will tend to choose the configuration with the least RES possible (the NGCC combinations), while in the case of decreasing annual plant 
costs the model will tend to choose a configuration with a high value of RES (OCGT combinations).

The total costs function influences the cash flow and profitability of the energy sources combination.

The combination cash flow $\left(\mathrm{FC}_{n}\right)$ for a generic period $n$ can be written in function of RES (E\%) as follows:

$$
\begin{aligned}
& \frac{\mathrm{FC}_{n}}{P_{f}}=\left[\text { pue }+\% E \cdot \mathrm{pu}, \text { inc } \cdot(1-\Delta \mathrm{ifr} \%)^{n}\right] \\
& \cdot\left(1+\frac{\% E}{1-\% E}\right) \cdot \mathrm{fc}, f \cdot 8760 \\
&- {\left[\frac{\% E}{1-\% E} \cdot\left(\frac{1}{N} \cdot \frac{\mathrm{cinv}, \text { int } \cdot \mathrm{fc}, f}{\mathrm{fc}, \text { int }}-\mathrm{crc}\right)\right.} \\
&\left.+\mathrm{CO \& M} \cdot(1+i)^{n}+\frac{\mathrm{cuc}}{\eta_{\text {nom }}}+\frac{1}{N} \cdot \text { cinv, } f\right] \\
& \cdot\left(1+\frac{\% E}{1-\% E} \cdot \frac{\mathrm{fc}, f}{\mathrm{fc}, \text { int }}\right)-\frac{\mathrm{OF}}{\mathrm{Pf}} .
\end{aligned}
$$

The financial costs function can in turn be expressed in function of RES $(E \%)$ :

$$
\begin{aligned}
\frac{\mathrm{OF}}{P_{f}} & =\frac{\operatorname{cinv} \cdot r \cdot[1+(1 / N) \cdot(1-n)]}{P_{f}} \\
& =\frac{\left(P_{\mathrm{int}}+P_{f}\right) \cdot r \cdot[1+(1 / N) \cdot(1-n)]}{P_{f}} \\
& =\left(1+\frac{\% E}{1-\% E} \frac{\mathrm{fc}, f}{\mathrm{fc}, \text { int }}\right) \cdot r \cdot\left[1+\frac{1}{N} \cdot(1-n)\right] .
\end{aligned}
$$

Taking the example of the NGCC + wind combination, the trend for cash flow in function of RES for the first year is as shown in Figure 10.

\section{Conclusions}

This paper presents a model for the selection of optimized sets of programmable/programmed energy source combinations, rather than pursuing the alternate strategy of reducing variability in the production of energy from the renewable sources.

The model makes a first choice among potential combinations of different renewable and programmable sources, based on technical criteria. The capacity of energy transmission is always assumed as adequate to accept the programmable energy source. In the case of real-time operational scenarios, the model assumes that the programmable source chosen is capable of supporting brief variations from the nonprogrammable generation plants.

Given the identification of the technically suitable combinations, for each combination the model then quantifies the maximum percentage of integration for the variable sources and the appropriate strategy to maintain stability in production. Once the coefficient of maximum integration is fixed for every combination, the model evaluates all the combinations through calculation of a series of technical, economic,

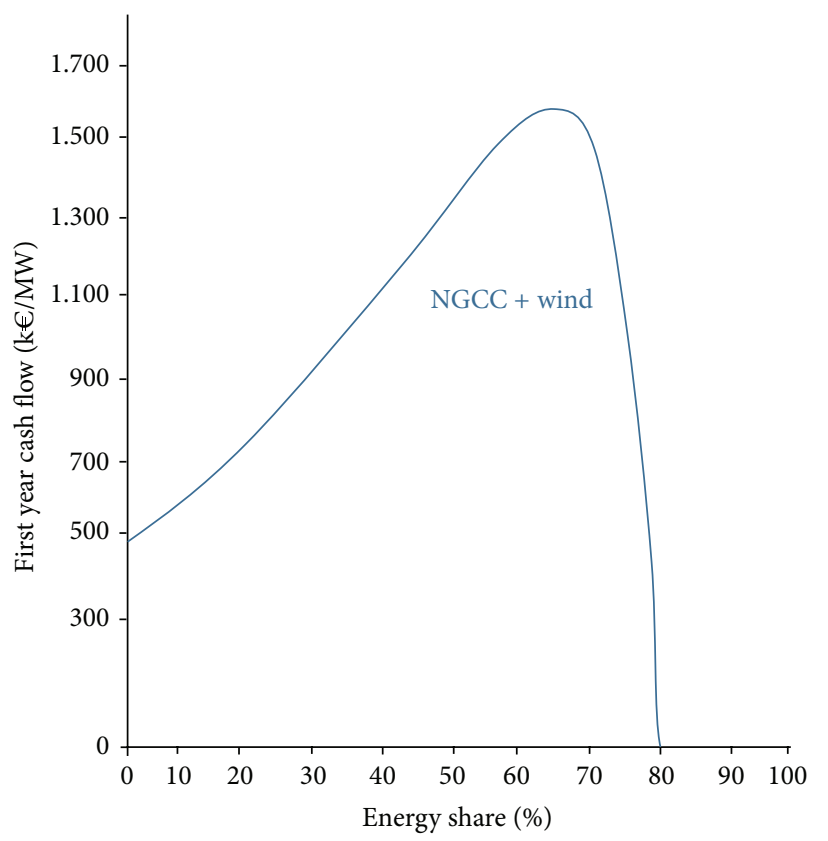

Figure 10: Cash flow for NGCC + wind combination.

and financial indicators, searching for the best possible configuration for each of the different combinations under consideration. Application of the model demonstrates that certain combinations and configurations are interesting from both an energy production and an economic point of view.

The study also provides an interdependency map illustrating the dynamics of the model and the main variables.

The data used for the simulation in the current paper are of generic character; however the model could now be applied to predict performance in specific real-world cases of hybrid energy systems.

\section{List of Symbols}

CC: $\quad$ Combination coefficient

$P_{\text {tot }}: \quad$ Total size of the combination

(MW)

$P_{f}: \quad$ Fossil based plant size (MW)

$P_{\mathrm{ti}}: \quad$ Technical integrated size (MW)

$\eta_{\text {avg }}$ : Fossil power plant annual average efficiency

$\eta_{\text {parz }}: \quad$ Partial efficiency at $P_{\text {tot }}-P_{f}$ size

$\mathrm{fc}_{\mathrm{int}}$ : Capacity factor of integrated energy source

$\eta_{\text {nom }}: \quad$ Fossil based plant nominal efficiency

$E_{f}: \quad$ Energy generated by fossil based plant

$\mathrm{fc}_{f}$ : $\quad$ Fossil based plant capacity factor

fc, $f$ : $\quad$ Fossil based plant capacity factor after integration

$E_{\text {int }}$ or $E_{i}$ : Energy generated by renewable plants

CUC: $\quad$ Fuel cost $(€ / \mathrm{MWh})$ 


$\begin{array}{ll}\text { cinv }_{i}: & \begin{array}{l}\text { Capital cost integrated power plant } \\ (€ / \mathrm{kW})\end{array} \\ \text { cinv }: & \begin{array}{l}\text { Capital cost fossil based power } \\ \text { plant }(€ / \mathrm{kW})\end{array} \\ \text { Ree: } & \text { Energy sale revenues } \\ \text { pue: } & \text { Average price of electricity } \\ & (€ / \text { MWh) } \\ \text { ifr: } & \text { Governatives subsidies for } \\ & \text { renewable generation }(€ / \mathrm{MWh}) \\ \% E: & \text { Renewable energy share } \\ \text { Max(Var. min-to-min) } & \text { Maximum variability min-to-min } \\ & \text { for the renewable energy source } \\ & (\% / \text { min) } \\ \% r: & \text { Ramp rate as percentage of fossil } \\ & \text { based size plant (\%/min) } \\ \text { Ctiu: } & \text { Combination overall annual cost } \\ N: & \text { Project lifecycle (years) } \\ \text { crc: } & \text { Fuel cost saving to renewable } \\ i: & \text { generation ratio ( } € / \text { MWh) } \\ \text { OF: } & \text { Inflation rate } \\ r: & \text { Financial costs } \\ \text { O\&M: } & \text { Debt interest rate } \\ & \text { Operations and maintenance. }\end{array}$

\section{Plants Acronyms}

IGCC: Integrated gas combined cycle

NGCC: Natural gas combined cycle

NGCC: Natural gas combined cycle flexible

OCGT: Open cycle gas turbine

OCGTf: Open cycle gas turbine flexible

PC: Pulverized coal

PV: $\quad$ Photovoltaic

CSP: Concentrated solar plant

CCS: $\quad \mathrm{CO}_{2}$ capture system

CC: Combined cycle

OGT: Open gas turbine.

\section{Conflict of Interests}

The authors declare that there is no conflict of interests regarding the publication of this paper.

\section{References}

[1] V. Calderaro, V. Galdi, G. Massa, and A. Piccolo, "Distributed generation management: An optimal sensitivity approach for decentralized power control," in Proceedings of the 3rd IEEE PES Innovative Smart Grid Technologies Europe, Berlin, Germany, October 2012.

[2] V. Calderaro, V. Galdi, A. Piccolo, and P. Siano, "Electric distribution systems and embedded generation capacity," in Proceedings of the 6th IASTED International Conference on European Power and Energy Systems (EuroPES '06), pp. 244-249, Rhodes, Greece, June 2006.

[3] V. Calderaro, V. Galdi, M. Cortes-Carmona, and R. PalmaBehnke, "Fuzzy load-shedding strategy in distribution systems," in Proceedings of the 11th International Conference on Intelligent Systems Design and Applications (ISDA '11), pp. 319-324, IEEE, November 2011.
[4] US Energy Information Administration, Annual Energy Outlook, EIA, 2014, http://www.eia.gov/forecasts/aeo/.

[5] B. C. Ummels, M. Gibescu, E. Pelgrum, W. L. Kling, and A. J. Brand, "Impacts of wind power on thermal generation unit commitment and dispatch," IEEE Transactions on Energy Conversion, vol. 22, no. 1, pp. 44-51, 2007.

[6] G. Ramachandran, Program on Technology Innovation: Integrated Generation Technology Options, Energy Power Research Institute, 2009, http://www.energync.net/Portals/14/Documents/ EnergyPolicyCouncil/2009_Prism_MERGE_Gen_Options_Report .pdf. 


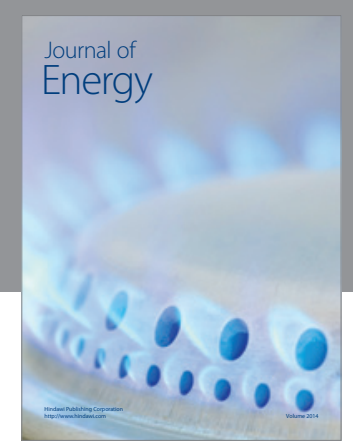

Journal of

Industrial Engineering
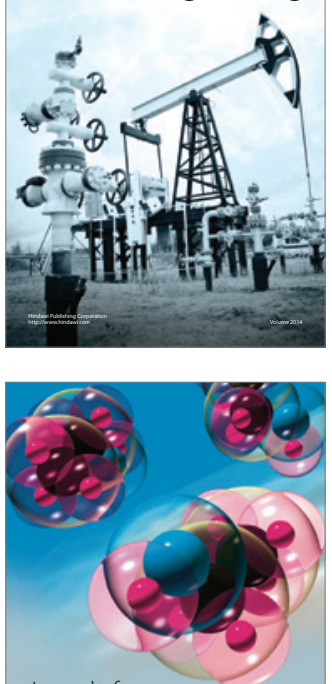

Fuels
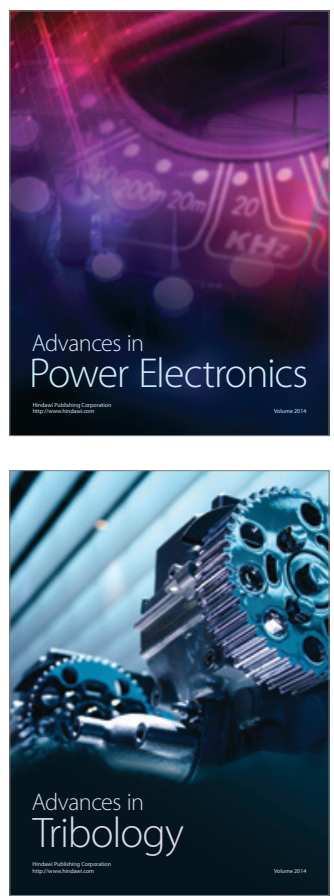

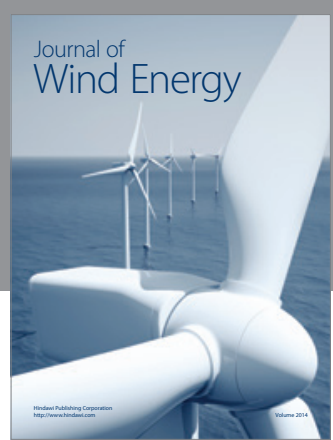

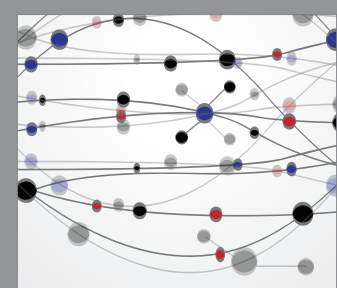

The Scientific World Journal

Submit your manuscripts at http://www.hindawi.com

Journal of

Structures
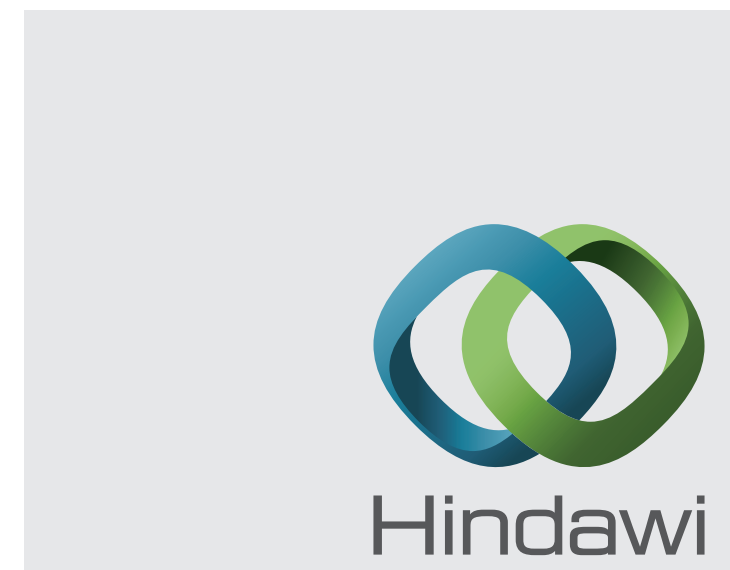

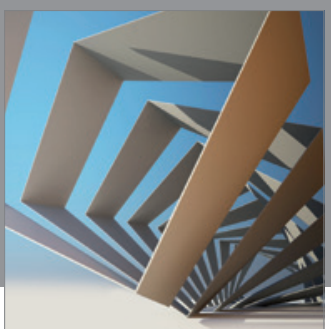

Rotating

Machinery
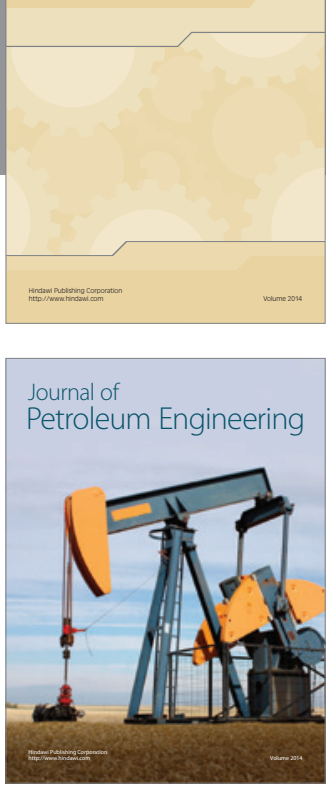

Journal of

Solar Energy
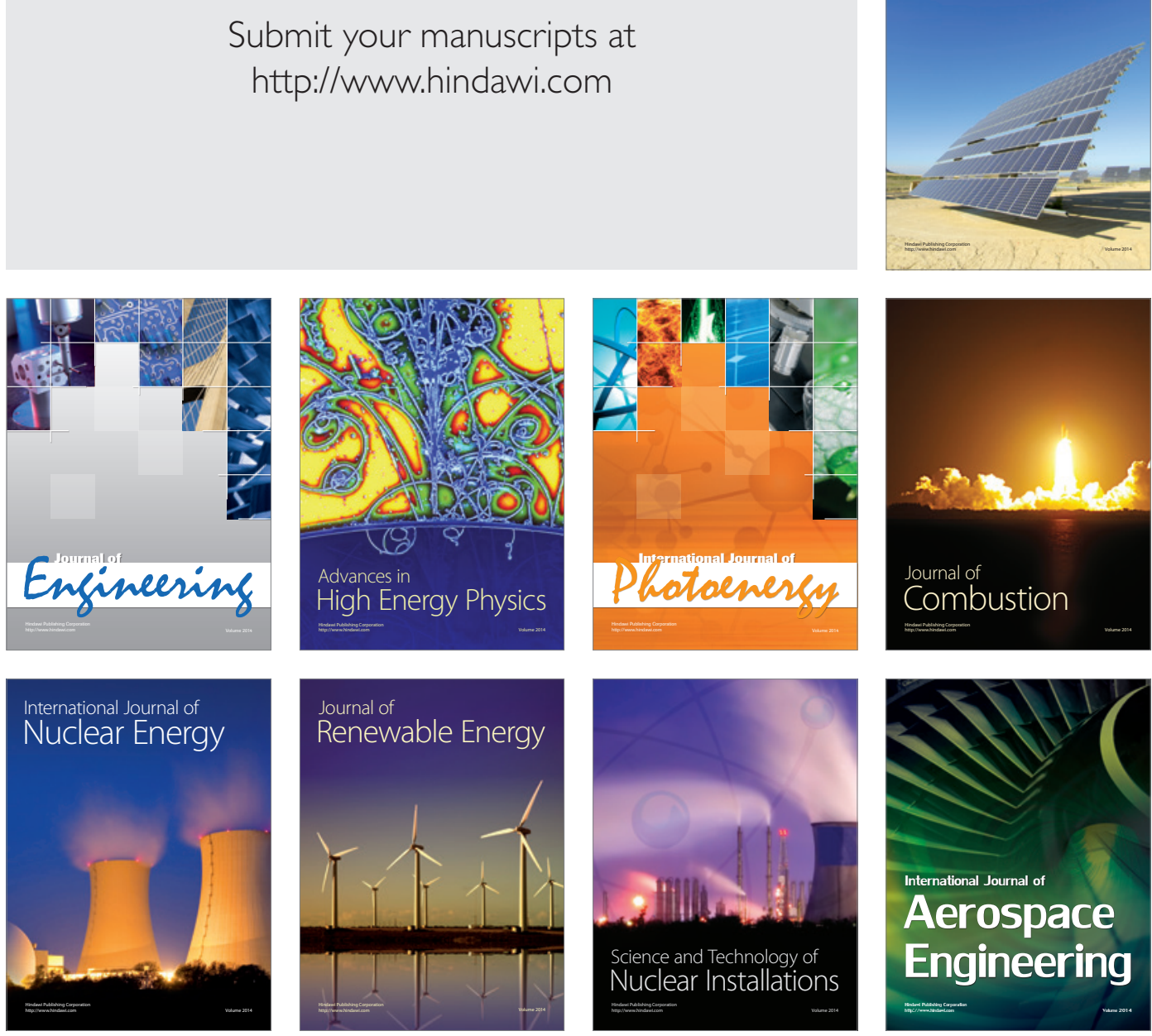